\title{
MULTI-STAKEHOLDER COLLABORATION IN URBAN FREIGHT CONSOLIDATION SCHEMES: DRIVERS AND BARRIERS TO IMPLEMENTATION
}

\author{
Daniela PADDEU ${ }^{*}$, Graham PARKHURST ${ }^{2}$, Gianfranco FANCELLO ${ }^{3}$, \\ Paolo FADDA ${ }^{4}$, Miriam RICCI ${ }^{5}$ \\ 1,3,4 Dept of Civil, Environmental and Architectural Engineering; University of Cagliari, Cagliari, Italy \\ ${ }^{2,5}$ Dept of Geography and Environmental Management, University of the West of England, Bristol, \\ United Kingdom of Great Britain and Northern Ireland
}

Received 30 May 2016; revised 23 September 2016; accepted 11 November 2016

\begin{abstract}
Due to the motivations of climate change, the health impacts of poor air quality, and the importance of cities for economic growth, transport policy at all levels of governance places emphasis on reducing and managing urban traffic and congestion. Whilst the majority of urban traffic is created by personal travel, freight vehicles make a relatively large contribution per vehicle to congestion, pollution and severe accidents. The European Commission (EC 2011) estimates that 6\% of all EU transport carbon emissions are from urban freight. For these reasons, a well-structured portfolio of measures and policies oriented towards more sustainable and efficient management of supply chain activities carried out in urban areas is needed, in order to reduce negative externalities related to urban mobility and improve economic performance. In recent years, there has been enthusiasm amongst commentators that shared-resource economic models can both create new commercial opportunities and address policy problems, including in the transport sector. Within the city logistics subsector, this new model is exemplified by the emergence of Urban freight Consolidation Centres (UCCs). UCCs replace multiple 'last-mile' delivery movements, many of which involving small consignments, by a common receiving point (the consolidation centre), normally on the periphery of a city, with the final part of the delivery being shared by the consignments in a small freight vehicle. Such arrangements can represent a good compromise between the needs of city centre businesses and their customers on the one hand (i.e. high availability of a range of goods) and local and global sustainability objectives on the other. At the same time, by sharing logistics facilities and delivery vehicles, UCCs offer added-value services to both urban economic actors, such as retailers, and network logistics providers. However, UCCs add to the complexity of logistics chains, requiring additional contracts, communications and movement stages. These arrangements also introduce additional actors within the supply of delivery services, notably local authorities present as promoters and funders, rather than simply as regulators, companies specialised in the UCC operation, and companies, which provide specialist technologies, such as electric delivery vehicles. UCCs therefore also represent an example of multi-stakeholder collaboration. Drawing on the results of a 2013 survey in Bristol (United Kingdom) and a further survey carried out in 2015 in Cagliari (Italy), the present paper will provide an in-depth comparison of the differences in the perceptions of urban freight users and stakeholders towards UCCs. Retailers involved in the survey carried out in Bristol showed high satisfaction with the delivery service provided by the UCC. Different topic areas (e.g. timeliness, reliability, safety) are examined through analyses of both qualitative and quantitative data. The survey carried out in Cagliari investigated the inclination of potential users to join a UCC scheme. The comparison between the two cities considers factors such as the nature of business holding (e.g. SME versus multiple retailers), operational practices (e.g. pattern of deliveries) and operating subsector (e.g. food versus no food). An analysis on the barriers to the implementation of UCCs in Bristol and in Cagliari is provided at the end of the paper.
\end{abstract}

Keywords: sharing resources, sustainable urban freight transport, urban freight consolidation centre, city logistics, case study.

\section{Introduction}

The world's population is being increasingly concentrated in cities; the urban population is expected to reach 6.3 billion by 2050 (UN 2012). The economic vitality of a city strongly depends on the efficiency of urban goods distribution (Browne, Allen 2011). However, freight transportation is a major contributor to climate change

*Corresponding author. E-mail: paddeudaniela@gmail.com 
and global warming and it contributes to about $5.5 \%$ of global greenhouse gas emissions (Zhang et al. 2018; McKinnon 2010). According to the European Commission (EC 2011), freight transport within the EU and associated international maritime freight activities will increase by $40 \%$ by 2030 and just over $80 \%$ by 2050 . The collaborative economy involves the pooling of economic assets so that they can be used by multiple agents, either synchronously, or asynchronously. The term is most often associated with the "platform capitalist" businesses such as Airbnb and Uber, which obtain revenues from connecting peer owners with peer renters and peer sharers. In a generally critical review of the "sharing economy" phenomenon, Martin (2016) identifies that although the transition has become "co-opted" by specific business interests. For example, this might occur by intermediary companies extracting a short-term profit through "rentier" behaviour in respect of monopoly access to market data. However, where collaborative strategies are long-term and for wider objectives, one of the potential benefits could be more sustainable resource utilization and consumption.

Whilst in the transport sector much of the high-profile attention is on shared mobility services for personal travel, collaborative city logistics solutions to reduce the negative externalities arising from increased freight motor vehicles in cities (Gonzalez-Feliu, Salanova 2012; Witkowski, KibaJaniak 2014) are a measure being promoted by policy actors including the EC. Urban freight Consolidation Centres (UCCs) involve the delivery of multiple consignments destined for a city centre to an interim location in the form of a consolidation centre operated by a third party on behalf of a collective of participating freight recipients. The warehouse infrastructure is hence shared, as too is the space in the vehicle operating the consolidated 'last mile' delivery rounds to the final destinations. The approach potentially enhances urban transport and economic sustainability in a number of ways:

- As the consolidation facility is normally located on the periphery of an urban area, large freight vehicles can remain on the strategic road network, avoiding high vehicle-specific emissions of noxious pollutants in urban areas where the population is most exposed to poor air quality. At the same time, reducing the number of large vehicles in urban streets, which are often too narrow for their effective passage, increases the efficiency of operation;

- The benefits are enhanced if the last-mile deliveries are made using an ultra-low emissions vehicle, such as an electric lorry or van (Van Rooijen, Quak 2010);

- System efficiency is improved, for example measured in terms of vehicle-km and energy consumption. Without the UCC, large vehicles make relatively long detours from the strategic road network to deliver what are often small individual consignments. Instead, provided there is sufficient participation in a UCC scheme by a range of end-receivers, the lastmile logistics can be organised in a highly efficient way, with relatively few rounds being made by vehicles that depart the depot with a high level of payload utilisation, all of which is destined for locations within a specific city centre;

- Besides traffic and environmental benefits, the UCC provides to the users a wide range of value-added logistics services that allow improving the efficiency of the supply chain and business performance (Verlinde et al. 2012), such as cost reductions, just-intime stock holding for businesses with tight space constraints on their own premises). Among the benefits, it is worth mentioning: delivery lead-time reduction, improvements in product availability and customer service, improvements in the transparency of the supply chain, a reduction in stock losses and maximisation of retailing space, which can result in an increase in sales (Allen et al. 2014).

As can be seen from the above account, this kind of measure can only be delivered as a multi-stakeholder initiative and operated in a multi-stakeholder environment. According to the analysis of the development of urban logistics spaces in southwest Europe carried out by Gonzales-Feliu et al. (2014), usually the main initiator of the project wants to reach a consensus among all involved stakeholders. However, the stakeholders have different needs and expectations (Taniguchi, Tamagawa 2005; Tseng et al. 2005; Witkowski, Kiba-Janiak 2014; Kiba-Janiak, Cheba 2011). Establishing the centre requires an actor in the role of policy-entrepreneur seeking system enhancements, which are oriented towards the "common good", for example, improving citizens' quality of life (Witkowski, Kiba-Janiak 2014). It would not usually be within the interests of a specific deliverer or recipient to invest resources (procuring a UCC facility and vehicle(s), and designing and promoting the service) in the context of a shared system. This coordinating role has generally been taken by local authorities, although a commercial or not-for-profit interest can perform it (for example in the context of an airport). According to Kiba-Janiak and Cheba (2015), Lindholm and Browne (2013), Taniguchi (2014), within the multi-stakeholder environment that characterises the urban freight transport system, local authorities represent one of the most important groups of urban freight transport stakeholders. A key reason why local authorities are normally involved as policy-entrepreneur in the context of city logistics is that participation is voluntary, so charges must be attractive, and hence revenues are low, which means subsidy must be provided by, or be procured by, the local authority. As highlighted by Gonzalez-Feliu et al. (2014), UCCs characterised by a private end-user (carrier-based or mono-user UCCs) have a simpler steering structure, whereas multi-user UCCs have some problems related to the economic sustainability of the scheme. However, those which reach economic sustainability and so remain operative over the long-term, do so due to solid coordination among stakeholders and the will to work together without imposing decisions. Stake- 
holder relations are clearly, though, only one success factor. As Kin et al. (2016) argue, an UCC is not going to be financially viable in a small urban area due to a lack of sufficient demand for freight transport; while, at the same time, transport operators are not willing to outsource lastmile deliveries for a large area with few delivery problems.

Moreover, the allocation of the costs (to the participants and local authorities) and the existence of consumer surplus, enjoyed by the logistics companies, which are customers of UCCs, creates a problem for the viability of UCCs as an effective policy idea and sustainable mobility practice. Paddeu et al. (2014) identify significant efficiency savings from the operation of a UCC in Bristol (United Kingdom), likely to amount to net social benefits, suggesting that the lack of thriving UCC implementations is due to market failure. The majority of UCCs can only be subsided for a short period due to the limited availability of subsidies, and therefore most have a short lifespan (Browne et al. 2005; Van Duin 2009). Therefore, identifying relevant stakeholders and their objectives, and evaluating the degree to which these objectives are met is essential to designing a business model for a shared system that can be more permanent (Zenezini et al. 2015). The search for minimal demand to make the distribution system economically viable, together with the analysis of different financing strategies (e.g. public-private partnership), is needed to provide decision makers with quantitative decision support for their needs. Indeed, the definition of a business model in order to define a viable economic strategy is needed for the development of urban logistics platforms (Gonzalez-Feliu et al. 2014). Given that the most tangible benefits in terms of cost savings arise to the logistics companies, and that not all potential participants in an UCC have need of additional or different services, it is not a surprise that many potential delivery-recipient users do not perceive the added value of the UCC scheme to them, and are therefore reluctant to pay for the service (Zunder, Ibanez 2004; Marcucci, Danielis 2008). Also, the literature does not provide a methodology for objectively measuring the added value of UCC infrastructures from the standpoint of sustainable development, even though the indirect benefits gathered by UCCs (e.g. savings in road maintenance, public health, or stress, all of which have implications for the public finances) should arguably be quantified in economic terms and monetised, in order to allow public authorities to justify investments by such savings (Gonzalez-Feliu et al. 2014).

In order to incentivise suppliers and retailers to join the scheme, local authorities can apply restriction measures (Verlinde et al. 2012), such as, for example, access restrictions for freight vehicles in terms of time-windows or routes. However, despite such restrictions, many carriers prefer not to use the UCC and directly supply their customers because they perceive the scheme as increasing their costs and reducing their profitability (Van Rooijen, Quak 2010). In fact, according to Köhler (2004), Patier (2006), Van der Poel (2000) and Van Rooijen, Quak
(2010), the justification for implementing measures such as UCC and freight traffic restrictions should be clearly communicated to the stakeholders involved in the urban context. For a successful UCC implementation, both suppliers and receivers should be convinced about the reason to change the current situation, because they usually are not fully aware of their responsibility for the environmental impacts associated with the deliveries they make and receive (Van Rooijen, Quak 2010).

Improved awareness of the consequences of current choices can only be one factor in a complex model of supply-chain decision-making, which is part based on individual judgement, part on corporate analysis. Some aspects, such as costs, may be shared, objective criteria; others, such as trust in the other actors may be personalpsychological, reflecting individual professional experience (AECOM/ITS 2010).

In addition to the economic consequences of participation, other forms of barrier also exist, such as at the institutional level. For example, Verlinde et al. (2012) identified that the likelihood of joining a UCC scheme strongly depends on the extent to which internal business practices would need to change. To some extent such barriers can be overcome by the engendering of cooperation and through effective consultation among the stakeholders involved (Verlinde et al. 2012). However, particularly relevant in the context of this paper, is that there may be limits specifically on the willingness to share logistics and transport resources (e.g. warehouse, delivery vehicles, etc.) with the other competitors, or indeed to divulge confidential corporate information about competitive best practices (AECOM/ITS 2010). According to Kiba-Janiak and Cheba (2015), cooperation among stakeholders can be effective when there exist "common interests and benefits for stakeholders"; they also pointed out as "regular communication and cooperation" in order to "getting to know stakeholders before planning a project" represent a key success. Learning about mutual expectations and problems and realize effectively common projects for the future could be the focus of long-term cooperation established by local authorities with the other stakeholders (Kiba-Janiak, Cheba 2015). This can be achieved by interacting of community members, sharing of experiences and designing of shared representations. Such practices and processes can be expected to develop and strengthen the interpersonal trust relations necessary for collaborative freight solutions to be accepted.

Having established the general conditions necessary for collaborative economy solutions to be successful in the freight sector, the paper now presents an analysis of two case studies; both are based on surveys addressed to retailers (actual users in the first case and potential users in the second one) involved. The first case analyses the UCC established in Bristol, an example notable for its longevity and therefore offering a rare example of resilience in this niche; the second analyses the behaviour of the potential users of a UCC proposed for Cagliari (Italy). The first case 
is related to non-perishable (non-food) products, whereas the case of Cagliari considers food last-mile deliveries and commercial activities related to the Ho.Re.Ca. sector (i.e. Hotels, Restaurants, Cafes).The paper aims to identify empirically and evaluate the perceptions and behaviour of an important target user group. In this way it identifies the key success factors and potential barriers to the implementation of UCC schemes from their perspective, on the basis that the success of sharing of urban goods transport strongly depends on the perceptions and inclinations of the stakeholders to participate. The paper is organized as follows. Introduction provides an insight into multistakeholder collaborative schemes more generally than just UCCs. Section 1 describes the methodology applied in the research reported in this paper and the theoretical framework used to evaluate levers and limitations to the implementation of sharing logistics in the urban context. Section 2 introduces the case studies to which the model is applied. Data collection and analysis is provided for each case study. Section 3 provides the description of the results of the two surveys. Comparisons between the different samples surveyed (e.g. nature of business, type of product delivered, category of shops, size of the sample, etc.) and characteristics of the delivery (e.g. frequency, time, size, etc.) are provided. Section 4 provides an analysis of the barriers to the implementation of sharing logistics and transport systems. Financial and practical barriers, social and cultural barriers and barriers related to the type of product to be delivered are analysed. Finally, the paper finishes with some conclusions.

\section{The potential of multi-stakeholder collaboration for urban freight solutions}

Collaborative solutions for transportation and logistics are growing in popularity. Collaborative strategies can be good solutions to improve the efficiency and effectiveness of urban logistics systems (Paché 2008). They are commonly used in the field of supply chain management (MontoyaTorres et al. 2016). Collaboration is possible when at least two actors share their efforts to reach a common objective. Collaboration in urban logistics requires confidence, trust, and information sharing between the actors involved in the process. However, collaborative strategies applied to urban freight transport remain less explored, especially when the commercial area of the city is characterised by poor infrastructure and small stores (Fransoo et al. 2017). For this reason, collaborative urban freight delivery is likely to become one of the most promising areas of study (Muñoz-Villamizar et al. 2015). In order to improve the performance of the transport system in last-mile delivery (e.g. transport cost reduction, increase in vehicle utilization, etc.), a collaborative scenario is proposed. Collaboration is successful only if a full horizontal collaboration among companies takes place. According to Bahinipati et al. (2009), horizontal collaboration is a business agreement between two or more companies at the same level in the supply chain or network in order to allow ease of work and co-operation towards achieving a common objective.

Being collaborative means that companies have to share trucks, routes and customers in order to improve their individual turnovers by reducing transport costs, the number of necessary vehicles and offering in many cases a better service to customers, aside of reduce the environmental impact of the delivery activities (Muñoz-Villamizar et al. 2015). So, the main difference between traditional and collaborative UCC relies in full horizontal collaboration among stakeholders. Muñoz-Villamizar et al. (2015) pointed out that collaboration allows reducing emissions, costs, number of routes and improving vehicle utilization, so it uses more efficiently the available resources.

Before providing the definition of a model for sharing urban logistics systems, the present section provides an analysis of multi-stakeholder collaboration by considering different successful case studies related to urban freight multi-stakeholder collaborative schemes. As described in the introduction, the urban environment involves a great deal of stakeholders, each one with different needs and expectations. According to Verlinde et al. (2012), in order to make urban freight distribution more sustainable and efficient, at least one of the stakeholders involved has to make changes to his internal procedures and processes; it can be said that they have to change their "behaviour". Within the multi-stakeholder collaborative schemes, the most famous and widespread is the UCC. However, this section aims to provide an insight on collaborative schemes other than the more traditional UCC, which represents an additional transhipment point, often perceived as an added cost by its users. In general, even though a high participation of both receivers and carriers is essential for a successful implementation of a UCC scheme, the involvement of potential users is quite hard (Verlinde et al. 2012); in fact, receivers are reasonably pleased with the way they are delivered and, on the other hand, suppliers and carriers conform as much as possible to the needs of their receivers (Holguín-Veras et al. 2005). However, the addition of an additional transhipment point to the supply chain is not the only solution to consolidate urban freight flows more efficiently. In fact, it can be achieved by modifying the usual working methods of the stakeholders involved, in particular of carriers and receivers (Verlinde et al. 2012). The review of the most significant and successful examples of multi-stakeholder collaborative schemes provided by Verlinde et al. (2012), highlights that both receivers and carriers are only inclined to change their way of receiving/delivering if they think their own organizations will directly benefit from it.

Receivers highly influence the setting of the operational constraints that must be satisfied by carriers and shippers, because they are the primary customers. For this reason, changing the behaviour of receivers means to have upstream impacts on supply chains (Holguín-Veras, Sánchez-Díaz 2016). Receivers are usually more willing to be more willing to participate due to the benefits provided 
by a UCC scheme to the quality of the city environment, i.e. shopping is more pleasant for customers if there are fewer motor vehicles in the area (Verlinde et al. 2012; Holguín-Veras, Sánchez-Díaz 2016). However, there is a significant lack of knowledge about the roles played by the various economic agents involved in supply chains, and consequently, the most effective ways to make change (Holguín-Veras, Sánchez-Díaz 2016). Also, according to Holguín-Veras et al. (2005), the effectiveness of a policy depends on which agent is the target. In particular, they pointed out that policies that target carriers wishing they might influence receivers to change behaviour are not likely to be effective; while, on the contrary, policies addressed to the receivers lead to behaviour changes on the part of the carriers. This is because the receivers, being the most powerful agent, tend to impose their will on the carriers and, at the same time, carriers must be responsive to customers' demands if they want to stay in business (Holguín-Veras et al. 2008). As a result of the study carried out by Holguín-Veras and Sánchez-Díaz (2016), the use of regulation is less effective than voluntary programs. This is because the use of regulations to achieve a behaviour change is likely to force some participants to change operations and they perceive it as detrimental. On the contrary, voluntary programs encourage greater welfare because the participants that choose to adopt the measure are usually those that will benefit from it. The result is different if we talk about a shopping area belonging to a single landlord. In this case the imposing organisation (landlord) is able to control or strongly influence all the players and to make the solution successful, e.g. the UCC that serves Heathrow Airport (Browne et al. 2007).

Some shippers show reluctance to participating in UCCs. In fact, participating shippers lose control of their deliveries (by losing contact time with customers) and they do not use their own trucks, so they lose the opportunity to increase brand recognition. There is also a risk that this reduced presence in the delivery environment could result in them losing their customers to competitors. Doig (2002) recognized opposition from shippers as one of the key factors responsible for the end of the UCCs created by the Port Authority of New York and New Jersey (United States) as long ago as the 1940s.

In general, adaptations on the behalf of receivers have resulted in UCCs being successful in several cases. For example, within a Dutch project on demand-driven consolidation, deliveries to the retailers were made by the same supplier or carrier agreeing on a mutual delivery day or time; this meant carriers did not consider retailer's preferences when planning their delivery tours (SLDS 2005). Another successful example is that of the Swedish SMILE project, which involved $40 \ldots 50$ small food producers in the region with 5 purchasers in the city of Malmö (Sweden). Orders and deliveries were performed through a common food logistics system operated by both the producers and the purchasers. In this case, receivers and suppliers worked closely together in order to reduce the distance travelled by the fresh food supply. Also Binnenstadservice (BSS) represents a good example of UCC focused on receivers rather than carriers (Van Rooijen, Quak 2009). In this case it is retailers that decide to use the UCC, so suppliers basically have to change the destination address of their deliveries from that of the retailer to the address of the UCC. BSS involves small and independent retailers, which usually do not optimise their deliveries. It offers a free-of-charge delivery service (performed by environmentally friendly delivery vehicles) that allows retailers to save their time. Retailers can also benefit from extra services with fee at BSS, such as storage, homedeliveries, value-added logistics including retour logistics, possibilities for e-tailing in the city of Nijmegen.

Contrary to the receivers, carriers directly benefit from UCCs because every empty or half-empty kilometre represents a cost to them (Verlinde et al. 2012). Their willingness to join a UCC scheme might grow if they have clear evidence about the convenience of outsourcing lastmile deliveries, e.g. fleet optimisation, pick-ups at more convenient times (Kin et al. 2016). An example of a collaborative scheme that involves carriers is Teamtrans, a collaboration of 13 Dutch carriers who cover the whole Dutch territory by dividing it into 13 service areas based on postal codes (http://teamtrans.nl). With this project, each of the carriers serves one of these areas operating from his central depot. Carriers make deliveries to their own customers, but also to other carriers' customers that are in the area they serve. Another successful collaborative scheme is cargo pooling (http://www.trivizor.com; http:// www.mobimix-smartmove.be), which enables the renting of available space on freight vehicles by suppliers or carriers who want to deliver goods to a destination on (or close by to) the route of the vehicle. The system can be managed by means of a web-based platform able to combine free space with non-allocated cargo.

In general, according to Triantafyllou et al. (2014), cross-organizational collaboration allows improving service quality and cost reduction for businesses, but receivers have to set its operational scope in forming alliances with supply chain competitors to share assets, logistics, and expertise and exchange sensitive information. However, receivers might be dissuaded to participate because of losing control of the supply chain, additional costs, and poorer service standards. In contrast a high-potential opportunity might be that of a new shopping area development (Triantafyllou et al. 2014). On the other hand, logistics providers will have to develop common standards, content, and applications, which could be hard to achieve due to the fragmented and competitive nature of the logistics industry.

\section{Methodology}

Having established the potential for greater collaboration the paper now turns to investigate which drivers and barriers are related to the implementation of sharing logistics and urban freight transport policies involving multi-stake- 
holders, such as UCCs. Due to the key role assumed by receivers in the success of the implementation of sharing logistics systems highlighted in the previous sections, the focus of the paper is their perspective.

To highlight the relationships among levers and limitations of collaborative urban transportation and logistics sharing schemes, a conceptual framework is defined. The theoretical model is based on that proposed by GonzalesFeliu and Morana (2011), who considered socioeconomic and legislative factors related to collaborative sharing schemes. The model proposed in this section allows analysing drivers and barriers by considering the perspective of the actual/potential users involved: the receivers.

The description of the different components of the model and of their respective relationships is provided below (Figure 1):

- Drivers to the creation of urban logistics and transportation sharing schemes; this part provides compelling reasons for partners to join the scheme. According to Gonzalez-Feliu and Morana (2011), in the case of urban freight distribution, environmental objectives (such as $\mathrm{CO}_{2}$ reduction), economic efficiency, legislative reasons (e.g. access restrictions to the city centre, incentives to the sharing approach, etc.) and common interests are the main motivators to join a sharing scheme. Drivers strongly influence strategic and tactical decisions for all the stakeholders involved in the urban environment;

- Urban logistics and transportation solution; we consider UCC as a sharing solution to make urban freight distribution more efficient;

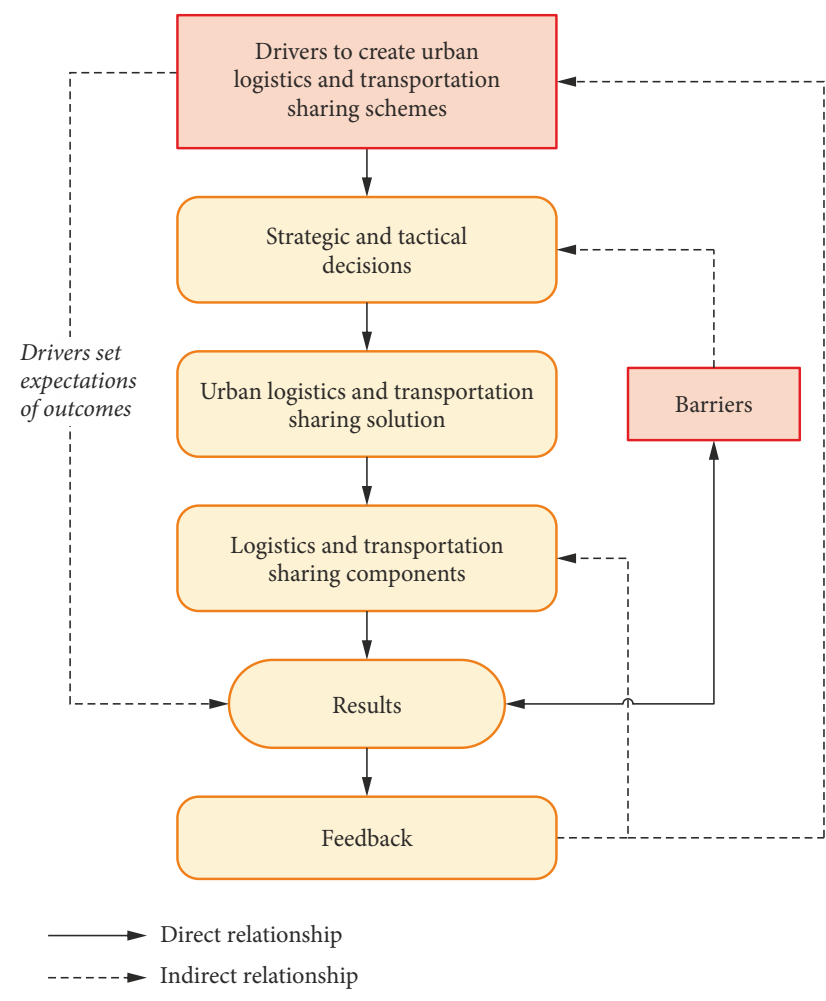

Figure 1. Conceptual model for sharing solutions applied to the urban freight distribution environment
- Logistics and transportation sharing components; this part considers the components of an urban sharing scheme. They strongly depend on the type of sharing solution system considered. Components include: stakeholders, vehicles used to make the deliveries, logistics facilities;

- Results are influenced by the sharing system components and by the barriers to the implementation of sharing schemes. Also, outcome expectations are set by drivers. Results provide feedback about the efficacy of the specific sharing scheme considered.

However, the paper aims to focus on analysis of the part related to the barriers to the implementation of sharing solutions to urban freight distribution and logistics. In particular, considering the UCC a good example of sharing solution, the authors decided to highlight the main limitations and obstacles to UCC by means of the analysis of two case studies: the city of Bristol and the city of Cagliari. Due to the different scenarios characterising Bristol and Cagliari (in Bristol a UCC has been operating for 14 years, whereas in Cagliari it is yet to be implemented), the research questions driving the two surveys are different. However, results are combined to answer to the common research question: "which are the drivers and limitations of a collaborative UCC scheme?".

The authors decided to adopt a case study approach in order to generate theory based on the analysis of rich evidence from particular instances (Eisenhardt 1989). Based on the analysis of the results of the surveys carried out in Bristol (in 2013) and in Cagliari (in 2015), the paper provides an in-depth analysis of the differences in the perceptions of urban freight users and stakeholders towards UCC. Factors, which can positively influence stakeholders' behaviour in order to join this kind of scheme and the barriers to their implementation are analysed. Taking the two case-studies together, the research questions were:

- How actual (Bristol) and potential (Cagliari) users perceive sharing collaboration systems (e.g. "what kind of benefits does a sharing system provide to my business?", "does it represent an advantage to my business?");

- Whether the inclination to join a sharing system depends on the type of products to be delivered, on the nature of the business to be involved, or on the culture of the users to be involved;

- What kind of issues can limit the implementation of sharing systems;

- How the organization of the sharing delivery system (e.g. delivery scheduling) can change depending on the type of product to be delivered and on the nature of the business.

The case studies mainly differ in terms of: existence of a UCC, type of products and nature of business (i.e. multiple retailers/SME).

The description of the case studies and of the data collection process is provided in Sections 3.1...3.4 for the case of Bristol and Sections 3.6...3.8 for the case of Cagliari. 


\section{Case study analysis}

\subsection{The case of Bristol}

Bristol is famed for its maritime history. It is the largest urban area of the South West of England, with an estimated population of 449300 in 2016 and around 500000 car movements every day in and out of the city centre, making it one of the most congested cities in the UK (Bristol City Council 2013). Part of this congestion, as well as part of the negative externalities related to road transport, is due to freight vehicle movements. Its local political emphasis on sustainable city solutions and achievements in some policy sectors led to it being selected as European Green Capital in 2015 (https://visitbristol.co.uk). The Bristol UCC is one of a suite of sustainable mobility policies, including the promotion of cycling and the use of electric vehicles (https://www.bristol2015.co.uk).

\subsection{The Bristol and Bath Urban Freight Consolidation Centre}

Bristol represents an interesting case-study of UCC longevity through the sequential use of grant funding from a series of EU and most recently UK national projects to maintain subsidy to the UCC (CIVITAS VIVALDI 2002...2006; START 2007...2008; CIVITAS RENAISSANCE 2008...2013 - indirect support though operating the UCC in partnership with the neighbouring authority of Bath and Northeast Somerset; Local Sustainable Transport Fund 2011...2016; http://www.civitas-initiative. org). In recent years the centre has also become the first in the UK serving two city centres. At the time of writing, there were 83 participating retailers in Bristol and 21 in Bath. The Bristol and Bath Urban Freight Consolidation Centre (BBUCC) is managed by DHL and deliveries are made by means of electric lorries, which further reduce polluting freight emissions. Deliveries are made 6 days a week, usually in the morning. Added services (e.g. storage, pre-retailing, recycling of cardboard and plastics) are offered by the BBUCC to users. Emission reductions in Bristol were identified as a result of sharing delivery vehicles for the final leg of the supply chain (i.e. last mile deliveries). $28677 \mathrm{~kg}$ of $\mathrm{CO}_{2}, 122.29 \mathrm{~kg}$ of $\mathrm{NO}_{\mathrm{x}}, 2.31 \mathrm{~kg}$ of $\mathrm{PM}_{10}, 20.32 \mathrm{~kg}$ of $\mathrm{CO}$ and $9854 \mathrm{~kg}$ of fuel were avoided as a result of the scheme (Paddeu et al. 2014). Due to the high quality results achieved in terms of pollution avoided and number of HGVs reduction and also to its long life (compared with the lifespan of the other UCC pilots in the EU), BBFCC can be considered a very successful example of the sharing economy applied in a urban, multistakeholder environment.

After the initial trial period (approximatively the first year of each project), which was free of charge due to the funds provided by the EU and by local authorities, the retailers involved in the scheme pay a fee for the service they receive. At the time of writing the indicative charges for use of the scheme were $£ 9$ per cage and $£ 12$ per pallet, but they are open to negotiation with specific participants.

\subsection{The survey in Bristol: data collection}

The survey data were collected as part of the CIVITAS RENAISSANCE project in 2013. The survey was addressed to participating retailers in order to highlight the drivers of multi-stakeholder collaborative shared freight delivery schemes. In particular, the survey aimed to understand what benefits existed for the retailers involved in the scheme, as well as the quality of the service provided by the BBUCC, as perceived by its users. The survey design and conduct included the following steps:

- choice of a sample of stores to which to administer the questionnaire;

- choice of method of questionnaire administration;

- questionnaire project;

- pilot questionnaire;

- administration and collection of the questionnaire (PA.PI. - Paper and Pencil Interviewing):

- administration with DHL (during deliveries to the outlets);

- administration by lone interviewer (visits independent of DHL);

- data preparation and analysis.

Most participating retailers are located in the adjacent shopping centres of Broadmead and Cabot Circus, in the core of the city centre. Although the population of all users is 81 retailers, just 21 retailers use the BBUCC intensively, and these were the ones selected for inclusion in the survey, in order to establish a study population of experienced participants.

The questionnaire was composed by 2 parts ( 25 questions in total). The first part aimed to define the characteristics of a typical delivery received by BBUCC (e.g. delivery time and frequency, size, type of product delivered, etc.). The second part aimed to investigate the satisfaction with the logistics and delivery services provided by BBUCC. In particular, the retailers were asked to express their satisfaction (on Likert-scales) with the following areas: delivery time, timeliness, delivery frequency, safety of the delivery and the overall service they receive. This second part of the questionnaire allowed the authors to define the factors (drivers) that can persuade potential users to join a collaborative sharing system. The questionnaire finished with a section of open-ended questions that aimed to collect qualitative data. The retailers were asked to explain the reasons for their satisfaction or dissatisfaction with the service by thinking about the aspects that they like or dislike the most. Also, they were asked to indicate the areas where they feel the BBUCC could perform better (by considering and comparing it to their previous delivery experiences).

\subsection{Results of the survey in Bristol}

The respondents comprised national multiple (chain) retailers. Categorised by product sold, they retailed:

- clothing/footwear (24\%);

- entertainment and technology (38\%);

- household goods (10\%); 
- cosmetics (14\%);

- jewellery (5\%);

- food and drink, chocolate (10\%).

The majority of the retailers involved in the survey (86\%) reported receiving deliveries from the UCC $1 \ldots 3$ times a week; $9 \%$ received deliveries $1 . .3$ times a month, and $5 \%$ received deliveries very often ( $4 \ldots 6$ times a week). However, $62 \%$ also reported receiving deliveries other than from the UCC, due to emergency reasons or to fulfil e-commerce orders.

In order of importance, the advantages indicated from participating in the scheme were: possibility of delivery to stock room, security of delivery, set delivery time, additional service provided (such as recycling of cardboard and plastics), staff time saved per delivery, duration of delivery, staff safety. Only one retailer indicated "costs" and no one indicated "sales".

\subsection{Satisfaction with the delivery service}

In order to understand if stakeholders are positive about sharing freight transport and logistics resources, it is very important to determine if they are satisfied with the service provided. Retailers interviewed in Bristol were asked to indicate their level of satisfaction (1-to-5 Likert-scale: 1 indicating low satisfaction and 5 high satisfaction) with the delivery service provided by the BBFCC. In particular,

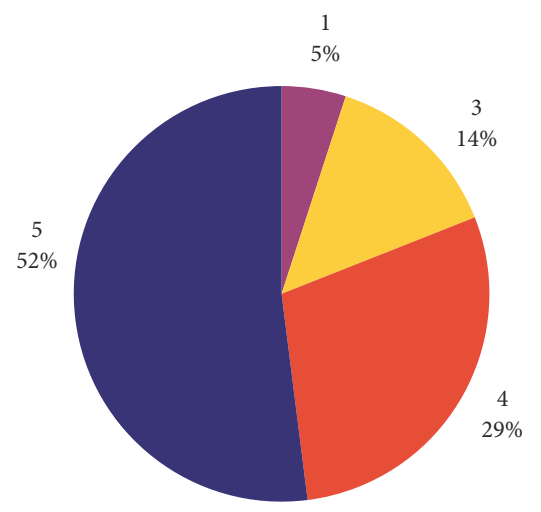

Figure 2. Satisfaction with the delivery time in Bristol: 1 - not at all satisfied; 2 - slightly satisfied; 3 - moderately satisfied; 4 - satisfied; 5 - very satisfied

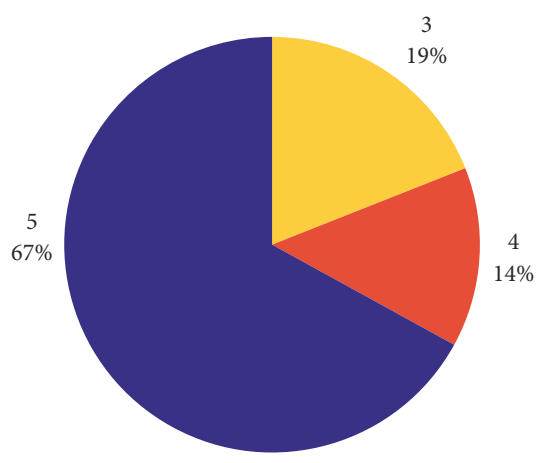

Figure 4. Satisfaction with the delivery frequency in Bristol: 1 - not at all satisfied; 2 - slightly satisfied; 3 - moderately satisfied; 4 - satisfied; 5 - very satisfied they were asked to indicate their satisfaction with the following areas (Figures 2-6):

- delivery frequency;

- delivery time;

- timeliness;

- security of delivery;

- overall service.

The interviewed showed high satisfaction level with all the areas investigated. In particular: 95\% declared to be very satisfied with the timeliness, $81 \%$ very satisfied with the delivery frequency and the delivery time, $90 \%$ very satisfied with the safety of the delivery, and $95 \%$ very satisfied with the overall service provided by the BBFCC. Qualitative data indicated retailers are very satisfied especially with the relations they have with the staff who manage the BBFCC; in fact, the staff was defined "very friendly and always willing to take time with the delivery" [...] "the delivery team is very friendly, helpful and always professional".

It is worth noting that human relationships are a key success in the case of Bristol; in fact retailers' trust in the BBFCC team. Probably, the high level of satisfaction is emphasised due to the positive relations among them.

Figures 2-6 show the satisfaction of the retailers in Bristol. They were asked to rate on a scale of 1 (not at all satisfied) to 5 (very satisfied), their satisfaction with the overall service provided by the BBFCC.

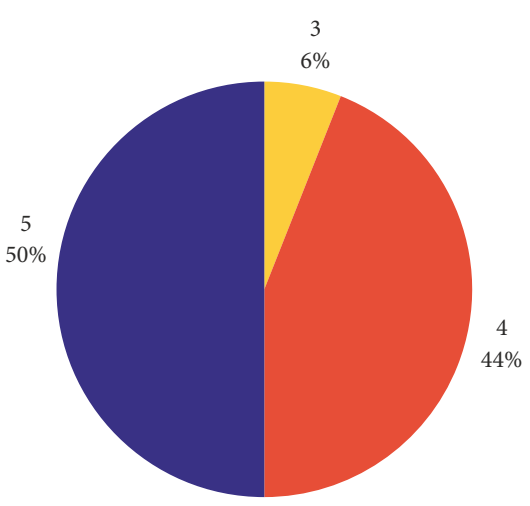

Figure 3. Satisfaction with the timeliness in Bristol: 1 - not at all satisfied; 2 - slightly satisfied; 3 - moderately satisfied; 4 - satisfied; 5 - very satisfied

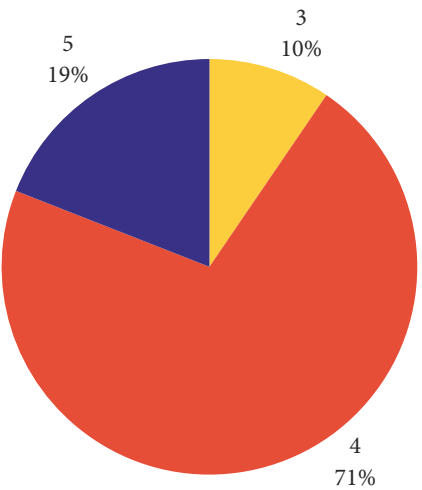

Figure 5. Satisfaction with the delivery safety in Bristol: 1 - not at all satisfied; 2 - slightly satisfied; 3 - moderately satisfied; 4 - satisfied; 5 - very satisfied 


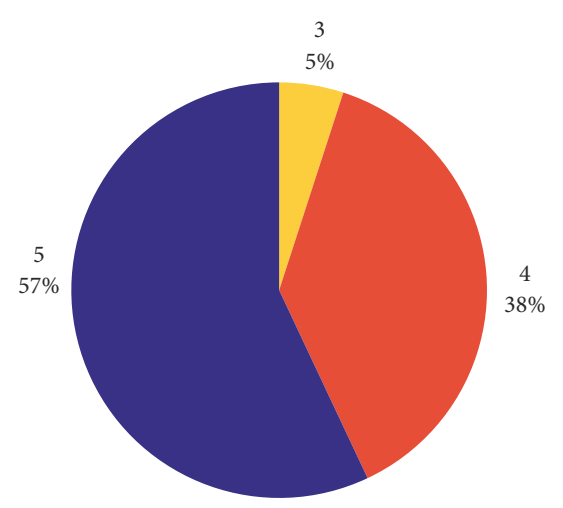

Figure 6. Satisfaction with the overall service in Bristol: 1 - not at all satisfied; 2 - slightly satisfied; 3 - moderately satisfied; 4 - satisfied; 5 - very satisfied

\subsection{The case of Cagliari}

Cagliari is an Italian city with 154460 inhabitants. It is the capital of the Autonomous Region of Sardinia and the main centre of its metropolitan area, which includes, in addition to the capital, several hinterland centres, and a total of 431302 inhabitants. Cagliari is located in the southern part of the island and tourism is a key economic sector.

Based on the results of a study on sustainable mobility in Italy, carried out by Euromobility (Bertuccio et al. 2015) under the patronage of the Ministry for the Environment, Land and Sea in 2015, Cagliari was among the top 10 cities in Italy for sustainable mobility: the first time for a city in the centre-south. Sustainable mobility measures implemented to date include car and bike sharing, together with traffic restriction measures. City logistics measures can be seen as a logical "next step" for transport policy to further reduce the negative externalities related to road transport.

\subsection{The survey in Cagliari: data collection}

The survey in Cagliari was carried out in 2015 within the project: "Development of an Organisational and Governance Model for City Logistics". The survey aimed to investigate levers and limitations to the potential implementation of collaborative sharing logistics solutions in the city of Cagliari. In particular, the survey focused on food deliveries. A specific area with high density of activities related to the Ho.Re.Ca. Sector in the city centre was identified. The area hosts 127 commercial activities, of which 66 traders agreed to participate to the survey (54\% of the study population). Some participants were interviewed by means of face-to-face interviews (PA.PI), others preferred to complete the questionnaire by themselves and have it collected later.

The survey included the following steps:

- census of the commercial activities located in the area and choice of the sample of stores to be involved in the survey;

- choice of the questionnaire administration;
- questionnaire design (2 questionnaires were defined: a longer one and a shorter one; the choice to administrate one rather than the other depended on the willingness to participate of the traders involved);

- pilot questionnaire;

- revision and modification of the questionnaire;

- administration and collection of the questionnaire;

- data preparation and analysis.

The data were collected in February and March 2015. Information about food deliveries was collected by considering five categories of commercial activities: restaurants, hotels, coffee shops, minimarkets and take-away. The authors designed two questionnaires: a longer one, consisting of 37 questions and an abbreviated version of the first one consisting of 8 items. Depending on the willingness of the interviewees to respond, the authors decided to administrate the first questionnaire or the second one. Both questionnaires aimed to define the characteristics of food deliveries by analysing: type of goods delivered, mode of delivery (self-supply or outsourcing or delivered by the suppliers), delivery frequency, time, size, etc. Information about fresh and non-fresh products was collected. Questions about nine different goods categories (i.e. fruit and vegetables, cured meats and cheese, meat, fresh bakery, fish, other dry goods, other fresh goods, beverages and other) were made. A specific section of the questionnaire investigated self-supply information and waste management. Qualitative data about goods delivery problems and needs, accessibility to the area, loading/unloading operations and parking were collected in the last part of the longer questionnaire.

\subsection{Results of the survey in Cagliari}

The survey allowed collecting quantitative and qualitative data. The sample is composed by businesses that belong to small and medium-sized independent enterprises (SME) that are open 6 days a week ( 7 days a week in summer). The category of shops surveyed in Cagliari can be categorised by considering the type of product sold, as follows:

- restaurants (33\%);

- coffee shops (26\%);

- minimarkets $(23 \%)$;

- take-away (11\%);

- hotels (8\%).

Contrary to Bristol, retailers surveyed in Cagliari were receiving perishable goods. The perishability of the goods delivered strongly influenced the characteristics of the delivery. In fact, deliveries in Cagliari are characterised by high frequency and small size (in order to guarantee the freshness of the products). Considering delivery mode, $14 \%$ of the sample reported providing for their deliveries themselves by means of their own vehicles (Self-Supply SS), whereas $20 \%$ reported all the goods they received were delivered by Logistics Operators (LOD). The others used a mixture of the two. 


\subsection{Delivery comparison}

Table 1 summarises the main differences between Bristol and Cagliari.

There are notable differences between the delivery patterns performed in Bristol and Cagliari. In Cagliari $42 \%$ of the interviewees receive most of the goods by deliveries made by LOD, whereas $43 \%$ used SS. On the other hand, all the deliveries to all retailers in Bristol were made by LOD (whether by the UCC or by other logistics operators). Another important difference relies in the delivery frequency. In fact, the majority of the interviewees in Bristol declared they received deliveries from the BBFCC with low frequency $(86 \%-1 \ldots 3$ times a week, $5 \%-4 \ldots 6$ times a week and $9 \%-1 \ldots 3$ times a month). They also reported receiving deliveries other than from the BBFCC $(67 \%$ of the sample), characterised by small size, due to e-commerce and emergency deliveries (deliveries that cannot be made by the BBFCC). In particular, $43 \%$ of them, receive these types of deliveries with high frequency $(36 \%-7$ or more times a week and 7\% - 4...6 times a week), 36\% $1 . . .3$ times a week and $21 \%$ less than once a month. In sum, if we consider all data collected in Bristol (related to both deliveries made by BBFCC and by other logistics operators), $38 \%$ of the retailers surveyed received deliveries with high frequency ( 7 or more times a week), 15\% $4 \ldots 6$ times a week, $31 \%-3$ times a week and $15 \%-1 \ldots 2$ times a week. However, deliveries made by BBFCC have a lower frequency with respect to the deliveries made by other logistics operators, although of larger size.

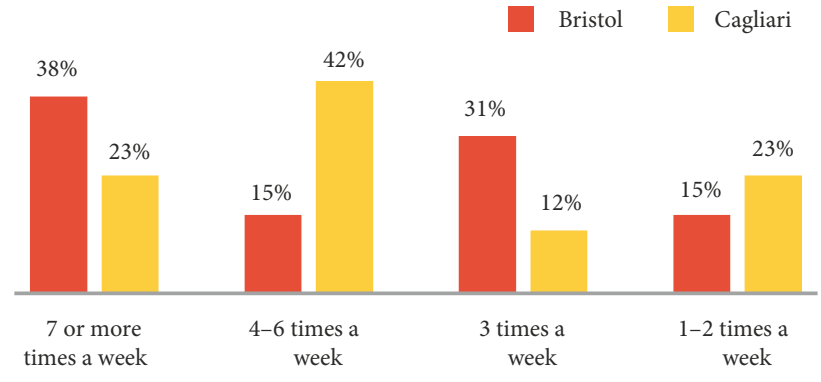

Figure 7. Delivery frequency in Bristol and in Cagliari

On the other hand, interviewees in Cagliari were receiving high frequency deliveries $(23 \%$ reported receiving deliveries 7 or more times a week and $42 \%-4 \ldots 6$ times a week). Figures 7 and 8 provide a comparison between delivery frequency in Bristol and in Cagliari.

With respect to the delivery time (Figure 8), the majority of the deliveries in Bristol are made in the morning (74\%); $16 \%$ of the deliveries are made both in the morning and in the afternoon, 5\% only in the afternoon and $5 \%$ only before 8:00 a.m. In general, deliveries are rarely made after 3 p.m. About the delivery time in Cagliari, also in this case, the majority of the retailers declared to receive deliveries in the morning (57\%), 5\% declared to receive deliveries before 8:00 a.m. and 7\% both in the morning and in the afternoon.

Another important difference is related to the delivery size. In order to be able to compare data related to the delivery size, the authors decided to consider a typical fruit

Table 1. Characteristics of the commercial activities in the two case-studies

\begin{tabular}{|l|l|l|}
\cline { 2 - 3 } \multicolumn{1}{c|}{} & \multicolumn{1}{c|}{ Bristol } & \multicolumn{1}{c|}{ Cagliari } \\
\hline Nature of business & Multiple retailers & SME \\
\hline Category of shop & $\begin{array}{l}\text { Clothing/footwear; } \\
\text { Entertainment and technology; } \\
\text { Household goods; } \\
\text { Cosmetics; } \\
\text { Jewellery; } \\
\text { Food and drink, chocolate }\end{array}$ & $\begin{array}{l}\text { Ho.Re.Ca. sector: hotels, restaurants, coffee shops, } \\
\text { minimarkets, take away }\end{array}$ \\
\hline Category of product & Non-perishable and no food (except for chocolate) & Perishable and non-perishable food \\
\hline UCC & Yes & No \\
\hline No surveyed shops & 21 (Bristol) $+16($ Bath $)=37$ & 66 \\
\hline
\end{tabular}

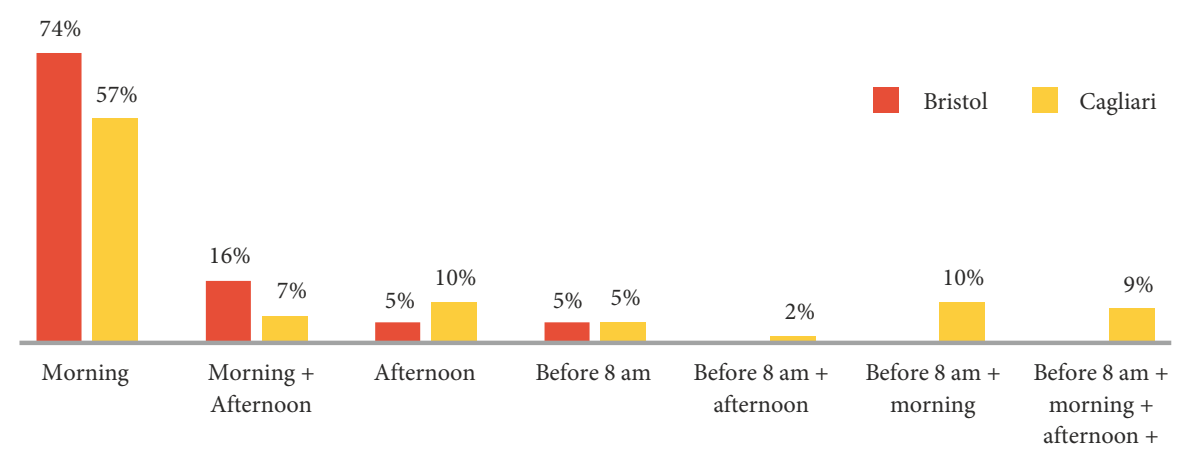

Figure 8. Delivery time in Bristol and in Cagliari 
box (length: $500 \mathrm{~mm}$; width: $300 \mathrm{~mm}$; height: $190 \mathrm{~mm}$ ) as reference load unit for both cases. While in Bristol the size of the delivery is related to the delivery frequency (high frequency corresponding with smaller size), in Cagliari there is no correspondence between delivery frequency and size. Due to the nature of the product sold (no food in Bristol and food in Cagliari), the number of boxes delivered in Cagliari is higher than in Bristol (Figure 9).

The last difference analysed concerns loading and unloading operations; we wanted to understand the behaviour of the delivery driver, in particular the place where delivery vehicles are parked during loading/unloading operations (Figure 10). In Bristol, the authors collected this data by means of their own observation, whereas in Cagliari the statements of the interviewees were examined.

Three categories of parking areas were considered:

- private loading/unloading area;

- public regular loading/unloading area;

- irregular parking (i.e. pavement, double parked, roadside, etc.).

There is a strong difference between the results in Bristol and Cagliari. In Bristol most delivery vehicles are parked in private loading/unloading areas (62\%) and 38\% are irregularly parked (not in fact a low rate). However, in Cagliari, the clear majority of the delivery vehicles were irregularly parked (88\%) and only $10 \%$ used public loading/ unloading areas (which were reported to be often irregularly occupied by vehicles not engaged in deliveries - i.e. parked private cars).

The analysis of the results highlighted a strong difference in the characteristics of the delivery service, especially in terms of: delivery mode (outsourcing/self-supply),

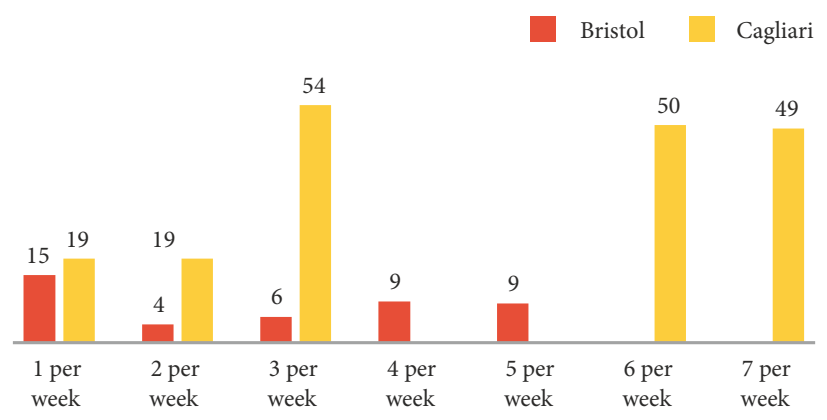

Figure 9. Number of boxes delivered on average per individual delivery in Bristol and in Cagliari

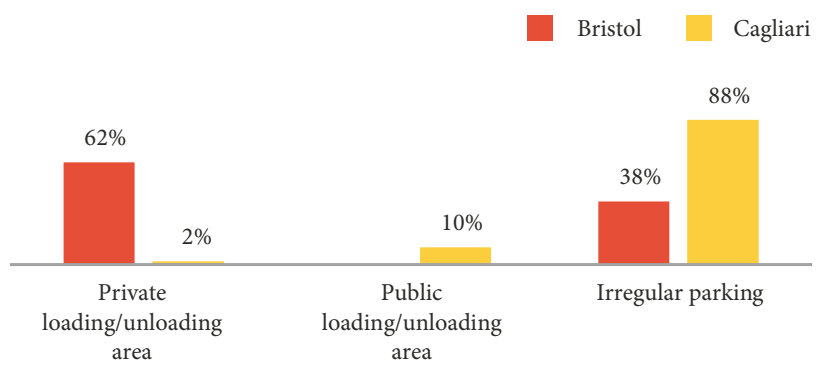

Figure 10. Location of vehicle for loading/unloading operations in Bristol and in Cagliari delivery size, delivery frequency and loading/unloading areas. Some of them, such as delivery size, delivery frequency and delivery mode strongly depend on the type of product delivered (food/no food).

A key difference in operating practices emerged from the two case-studies, in large part arising from the study of different sectors in the two cities.

\section{Lesson learnt from the application: drivers and barriers to implementing sharing freight transport and logistics resources in Cagliari and Bristol}

Based on the analysis of the literature and the results achieved in Bristol and Cagliari, in this section potential drivers and barriers to the implementation of sharing freight transport and logistics solutions for urban freight distribution are identified. In fact, more than 200 experiments have been developed in Europe, but only 15 UCCs were still active after 5 years of life (OECD 2003) and it is important to understand why these good theoretical solutions often fail in the real world.

\subsection{Drivers to the implementation}

\subsubsection{Drivers related to economic advantages}

As highlighted by the literature review, some economic advantages are related to sharing logistics (e.g. time savings, space savings, additional services, etc.). When retailers interviewed in Bristol were asked to indicate the advantages for their businesses of participating in the scheme, they reported "delivery to stock room" as being the most important benefit. In fact, BBUCC directly delivers goods to the stock room, allowing retailers to save staff working time. Retailers perceive it as an economic advantage to their businesses.

Second, they reported not needing a large space to stock the goods into the stock room due to the UCC, so they could reduce the size of the stock room and use almost all the space available directly for sales activity. This represents a very important economic benefit: retailers can enjoy just-in-time service provided by the UCC and as well as expanding sales space, have the alternative option to save rental costs by using smaller premises.

Also, due to the fact that city logistics measures are usually accompanied by traffic restriction measures applied to the access of motorised vehicles to the city centre, being part of a logistics and transportation sharing scheme could be an advantage to receive goods more easily. Moreover, during the first phase of BBUCC operation, European Commission and Local Authority funds supported the UCC trial and retailers did not have to pay to receive the deliveries. This incentivised the retailers to join, because they could save money during that period. After that, they started paying, but they recognised the value of the benefits in choosing not to leave the scheme.

Another important advantage is related to additional services provided by the BBUCC, such as recycling. In 
fact, BBUCC collects cardboard and plastics (packaging) from the retailers. Interviewees declared they perceive it as an advantage because they do not have to worry about waste handling. At the same time, BBUCC sells the cardboard collected, so it represents a source of income.

\subsubsection{Drivers related to practical advantages}

According to Kin et al. (2016), stakeholders could be persuaded to join the scheme in order avoid inefficient last mile deliveries. An important practical advantage is related to time saving. Most of the retailers interviewed in Cagliari reported having very little time flexibility, due to the high demands of their work. For this reason, they potentially would prefer someone else to deal with the orders, the purchases and above all with the deliveries. A more detailed analysis of retailers' satisfaction is provided in Paddeu et al. (2017). However, due to the high quality standards they demanded for their goods, they expressed considerable doubts about the likelihood of allowing someone else to undertake the selection for them: they would want to be sure about the quality of the products they were buying, so would need to check them before collecting goods. They would need "somebody to trust". In this case, thinking about the qualitative comments collected through the survey carried out in Bristol, retailers there were particularly happy about the BBUCC delivery staff, thought to be completely reliable, in terms of both timeliness and delivery safety. This might suggest that a trusted intermediary at least for the collection and delivery function, if not also the ordering function, might be a factor to convince retailers to join a shared logistics system in Cagliari.

Setting delivery times was recognized as being a very important advantage for the retailers in Bristol. In fact, they declared that they could receive goods at the time they preferred, so avoiding the receipt of goods during peak hours (i.e. when there are more customers in the shop). This can be an advantage also for the retailers in Cagliari, because they tend to go to buy and collect goods during off-peak times. Were they to be part of a shared logistics scheme, perhaps involving both facilities and vehicles, they could decide to receive goods when they wanted, not necessarily the same time as when it is easiest for them to make the collection journey.

\subsubsection{Drivers related to the protection of the environment}

Pollution and climate change are policy problems of high global interest (Walker et al. 2008). These issues are increasingly influencing people in the way they buy products, for example through endorsing "environmentally friendly" companies. For this reason, sustainable practices and green logistics are strongly considered by companies that want to be able to demonstrate that their own supply chains have as low an impact on the environment as reasonable possible. This is the case of the multiple retailers in Bristol. In fact, they declared they participated in the
BBUCC scheme because it provides a "green image" to their businesses, or because it realised the ethical principles of the company (qualitative data collected through the survey). In fact, as explained in Section 3.2, BBUCC allowed reduced polluting emissions and negative externalities related to urban freight transport. It can be used as a good example of collaborative multi-stakeholder solution able to improve the quality of life of a city centre. Also in Cagliari, when retailers were asked if they were willing to participate in a project that aims to make urban freight deliveries more sustainable, the majority of them replied "yes". Some of them were already receiving some deliveries by the cycle logistics provider Bicycle Xpress 2.0. However, the attraction of the "green image" did have its limits: interviewees were concerned about the costs related to a UCC service, some stating that they would be willing to participate only if the costs were not higher than those of their current arrangements.

\subsection{Barriers to the implementation}

\subsubsection{Financial and practical barriers}

Despite the UCC creating an overall cost reduction (e.g. reduction of delivery costs for the suppliers, of stock room space for the retailers, of social costs related to air pollution for the society, etc.), probably the main barrier related to the success of a UCC is exactly related to costs and in particular to its economic sustainability. In fact, in the most cases UCC requires initial funding from central or local authorities to start (e.g. for initial trials and research work) and when these subsidies are cut, often a UCC is unlikely to continue with its operational activities, due to the lack of financial resources (Browne et al. 2005; Allen et al. 2012). According to Zunder and Marinov (2011), it is still difficult to understand if a UCC could operate without subsidy. Also, due to the complexity of the competitive urban freight transport market it is difficult to find a suitable business model (Dablanc 2011; Kin et al. 2016). As found by Kin et al. (2016) for the case of Antwerp, for the UCC this means that even if users pay a fee, the breakeven required to reach a sustainable business volume is substantial.

In the case of Bristol, the BBUCC was subject to a high amount of investments covered by EU and Bristol City Council. When the EU projects finished, Bristol City Council was able to fund the subsidies from other grants; however retailers started paying a fee for the services provided by the BBUCC, so that the operational costs of the BBUCC were in part covered by the Council and partially by retailers. So, even though the case of Bristol to date represents a successful example of UCC, it still depends on public subsidies as it has not reached a critical mass of demand. This suggests the intervention and participation of Cagliari local authorities (for both financial and marketing support) is essential for the success of a UCC in Cagliari.

Sharing resources allows making their utilisation and consumption more sustainable (e.g. air pollution and noise reduction, congestion reduction, fewer accidents 
etc.) and it implies important social benefits. They should be quantified in economic terms in order to give local authorities and citizens an indication of the social costbenefit balance (i.e. money spent for the implementation versus costs suffered by the community due to negative externalities in urban areas). However, as pointed out by the manager of the BBFCC, the stakeholders' willingness to participate in this type of scheme is influenced by their expectations of who should sustain the costs. This can be considered strictly related to social and cultural barriers, which are described in the following section.

\subsubsection{Social and cultural barriers}

During the launch and the initial phase of a UCC operation, a major effort for recruiting retailers is required. In fact, despite of its success, BBUCC is not able to enlarge its market horizons, even though continuous marketing occurs. This can be attributed to scepticism to new delivery systems. Most of the retailers interviewed in Bath before the implementation of the BBUCC scheme reported satisfaction with their delivery services and that they did not want to change. So, even if they had to pay for their traditional delivery service and the new delivery service proposed by BBUCC was free of charge (during the EU project) and additional services were provided, they were not willing to join the scheme. Innovation and change can deter people.

No doubt willingness to participate is influenced by the nature of the company involved. As noted above, companies with strong ethic values stances can encourage participation in an UCC scheme. However, whilst larger companies may have active 'corporate responsibility' objectives, based on the experience in Bristol, the involvement of a large company is difficult to achieve, due to the centralised systems used to manage and schedule orders and deliveries: outlets are often remotely managed by a head office, which it is hard for the UCC manager to have direct contact with. On the other hand, a small business can be directly contacted, so potentially easily involved. However, probably because of the business size, the manager of a small company may be more risk adverse and may be faced with a larger change in his/her business management than would a large retailer. So, if they are accustomed to a specific and traditional scheme, they may be unlikely leave it. The person being interviewed in Bristol was the manager of the store, which was not responsible for the orders (a head-office decision based on sales reports); on the other hand, the interviewees in Cagliari were the people responsible for the commercial activities, which usually corresponded to the owners. In Cagliari, interviewees were responsible for their orders, purchases and usually also for the deliveries.

Another important dissuasion factor relates to competitiveness. Retailers may be not willing to share logistics facilities and delivery vehicles with their competitors. In this sense, sharing resources can be perceived as a dis- advantage for the business competitiveness, because resources, costs and benefits are shared, proportionally with the delivery size, with the competitors. This can be more significant in the case of Cagliari. In fact, when retailers were asked to indicate their willingness to join a shared delivery service, the majority of them seemed not to be totally convinced to want to use the same vehicles of the other commercial activities, their competitors. This may be related to the mistrust afflicting some commercial operators. However, contrary to what some retailers can think, the sharing economy can be a successful tool and key to competitiveness for participating businesses due to cost savings (Zunder, Ibanez 2004; Marcucci, Danielis 2008). Also, due to the cooperative consumption sharing and the related pollution reduction, the whole community benefits from it. Another category of stakeholders involved in the urban freight transport system is represented by carriers. Also in this case, they are often not willing to join this type of scheme because they cannot see the profitability potential; in fact, demand uncertainty is related to economic uncertainties for them and this represents a deterrent for their participation.

As demonstrated in the case of Bristol, receivers recognise who makes the deliveries (they often even know the names of the delivery staff) and they trust them. Direct contact is an important strategic key for a carrier company and they do not want to lose it. In this sense, maybe a large transport company, more than a carrier company, can perceive UCC as net-beneficial because of the significant cost saving overcoming the more remote interface with the customer.

\subsubsection{Barriers related to the type of good to be delivered}

There are not many cases of food-product UCC. In fact, logistics and transport of perishable goods could be more problematic to manage, due to the high quantity of goods to be delivered and the needs related to this type of product (e.g. breaking up the cold chain). Also, traders related to the food sector often lack confidence with the delivery services of logistics operators and prefer to be in charge of their own deliveries. This is strongly the case in Cagliari, perhaps intensified by the high value placed on gastronomic culture in Italy.

\subsection{Summary of the highlights}

This section provides a summary of the factors highlighted as responsible for driving or limiting the implementation of shared logistics systems. Table 2 summaries the main factors that can and might foster implementation in Bristol and Cagliari. On the other hand, Table 3 summarizes the barriers. A definition of the model that considers the relationships among sharing systems and the barriers/ drivers to their implementation is provided at the end of the section (Figure 11). 
Table 2. Summary of the main drivers highlighted in the cases of Bristol and Cagliari

\begin{tabular}{|c|c|c|}
\hline Drivers & Bristol & Cagliari \\
\hline Economic advantages & $\begin{array}{l}\text { Delivery to stock room; } \\
\text { Just-in-time service; } \\
\text { Cost reductions; } \\
\text { Public subsides; } \\
\text { Recycling }\end{array}$ & $\begin{array}{l}\text { Economic advantages in Bristol used as an evidence } \\
\text { of potential benefits for users }\end{array}$ \\
\hline Practical advantages & Set delivery time & Saving time spent self-sourcing \\
\hline $\begin{array}{l}\text { Protection of the } \\
\text { environment }\end{array}$ & $\begin{array}{l}\text { Environmental sustainability in line with ethical } \\
\text { principles of companies; } \\
\text { "Green Image" (marketing) }\end{array}$ & $\begin{array}{l}\text { Environmental sustainability in line with ethical } \\
\text { principles of companies }\end{array}$ \\
\hline
\end{tabular}

Table 3. Summary of the main barriers highlighted in the cases of Bristol and Cagliari.

\begin{tabular}{|l|l|l|}
\hline \multicolumn{1}{|c|}{ Barriers } & \multicolumn{1}{|c|}{ Bristol } & \multicolumn{1}{|c|}{ Cagliari } \\
\hline Financial and practical & $\begin{array}{l}\text { Economic unsustainability; } \\
\text { Dependence on public subsides; } \\
\text { Need of a good business plan; } \\
\text { Lack of effective marketing campaign }\end{array}$ & $\begin{array}{l}\text { Financial support of public authorities; } \\
\text { Lack of monetary quantification of benefits for all } \\
\text { the stakeholders }\end{array}$ \\
\hline Social and cultural & $\begin{array}{l}\text { Reluctance to change the delivery service; } \\
\text { Nature of the business (big companies vs small } \\
\text { companies); } \\
\text { Lack of quantification of profitability for carriers; } \\
\text { Carriers miss the direct contact with receivers }\end{array}$ & Competitiveness \\
\hline $\begin{array}{l}\text { Type of good } \\
\text { delivered }\end{array}$ & $\begin{array}{l}\text { No problems with non-perishable (or no food) } \\
\text { products }\end{array}$ & $\begin{array}{l}\text { Problems with the management of the deliveries } \\
\text { of perishable products (cold chain); } \\
\text { Higher costs for the cold chain }\end{array}$ \\
\hline
\end{tabular}

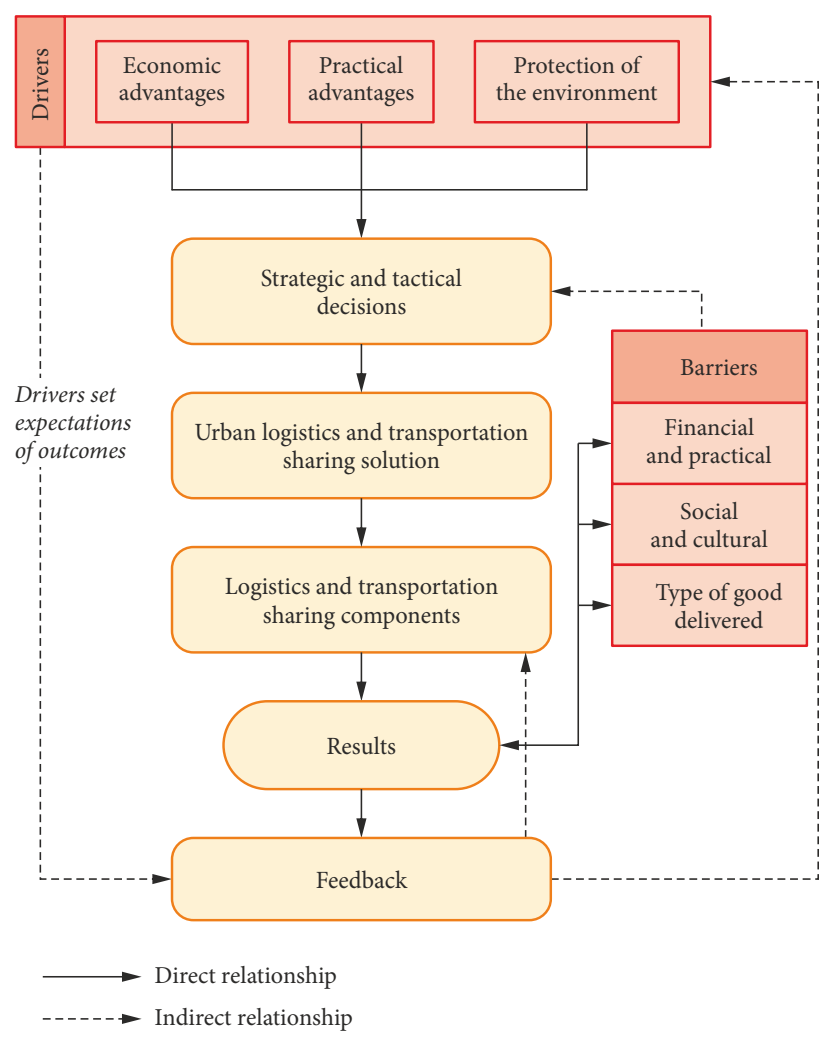

Figure 11. Urban sharing logistics and transportation model: drivers and barriers to the implementation

\section{Conclusions}

Based on the concept of the sharing economy, multistakeholder collaboration in urban freight transport can represent a successful tool to improve the quality of life of cities. An example of this kind of approach is that of city logistics and in particular UCC. Stakeholders' participation is essential for the success of a shared delivery system. By sharing logistics facilities and delivery vehicles, stakeholders can benefit from the UCC in terms of cost and time savings and added value services. However, stakeholders involved in the urban system have different needs and objectives. This is the reason why most of the UCC schemes in Europe have been promoted and financed by policy makers in their initial phases and the ceased operation when the subsides ended (Van Rooijen, Quak 2010). The sharing economy provides flexible opportunities for cost savings, pollution reduction and social value. However, as highlighted by the results of the survey carried out in Cagliari, despite the benefits it can potentially provide, it remains far from being universally accepted by potential users. The paper has provided an analysis of two multistakeholder schemes and a comparison of their inclination toward shared logistics facilities and freight transport vehicles. The analysis highlights that important benefits are provided by the UCC in Bristol, in particular in terms of reduced polluting emissions. Also, stakeholders involved 
in the scheme were very satisfied with the delivery service and the added services provided by the UCC. They recognised they achieve economic and practical benefits thanks to the BBUCC. However, despite the benefits coming from the UCC, there are significant problems related to its financial sustainability, which has been identified by the literature review (Gonzalez-Feliu et al. 2014; Browne et al. 2005; Allen et al. 2012) and by the analysis of the results in Bristol as the most important barrier to UCC operation.

It should be emphasised that most of the stakeholders interviewed for the BBUCC case-study were not in fact aware that they were part of the scheme. Communication and promotion campaigns should be organised to sensitise stakeholders to the benefits the sharing economy can provide to their businesses.

Cost allocation is another issue related to the success of shared logistics systems. This is not easily resolved: a specific analysis related to the identification of who benefits from the UCC is needed. "Who pays what" should be clear for all the stakeholders involved and costs should be allocated proportionally with each stakeholder's benefits.

Another important barrier is related to the propensity to change and risk acceptance/aversion. However, based on the results of the survey in Bristol, it is worth noting that large companies may be willing to participate in shared logistics schemes due to the "green image" they provide to the firm.

Last but not least, the case of Cagliari highlighted the type of goods to be delivered as a major barrier to the feasibility of a shared logistics scheme, for example for food products, due to the needs and constraints related to the cold chain (i.e. higher management costs, short delivery times).

Beyond the essential ingredient of political will, the decision to establish a UCC is related to a subset of decisions, such as the choice of the right location, an analysis of the current infrastructure level of the region involved, benefits and competitive conditions for business to be included and the relative economic effects in the region. Establishment of the scheme also requires the engagement of an experienced freight logistics operator (as in the case of Bristol) that identifies UCC as an opportunity, despite it being a small niche for an industrial sector increasingly dominated by national and international companies. For effective operations, there must be a sufficiently large pool of freight recipients that recognize the benefits of UCC participation (Kin et al. 2016). Generally, the value of these benefits is to some extent marketised through participants' willingness to pay additional delivery costs. The customers of UCCs have generally been city centre businesses and institutions such as retailers, hoteliers, and hospitals, although in principle could involve individual citizens, for example seeking control over when deliveries are made to their residences. The involvement of freight carriers - those charged with responsibility for completing the individual deliveries - is also required, but they can be expected to follow the instructions of the consignor/consignee and in any case is the only group of actors, which is strongly incentivized to use the UCC: they benefit from time and fuel cost savings by not entering the city (Verlinde et al. 2012). In fact, even if the last mile represents the shortest part of the supply chain for a manufacturer or for a transport company, it represents $28 \%$ of the total delivery costs for carriers (Goodman 2005). This potential for major efficiency savings suggests a combination of innovation, new technologies and professional commitment suggests the sector will continue to seek ways around barriers to "smarter" city logistics.

\section{Acknowledgements}

The authors would like to acknowledge the support given by the European Commission to the operation and evaluation of the BBUCC through the CIVITAS VIVALDI and CIVITAS PLUS RENAISSANCE projects and the support given by the Autonomous Region of Sardinia to the development of the research project in Cagliari, within the programme "Legge Regionale 7 Agosto 2007, N. 7: Promozione Della Ricerca Scientifica e Dellinnovazione Tecnologica in Sardegna".

\section{Funding}

The authors would like to thank Bristol City Council. Bath and North East Somerset Council and DHL for supporting this research project and acknowledge the support given by the European Commission to the operation and evaluation of the BBFCC through the CIVITAS VIVALDI and CIVITAS PLUS RENAISSANCE projects. They would also thank the Autonomous Region of Sardinia, which funded the survey carried out in Cagliari within the programme "Legge Regionale 7 Agosto 2007, N. 7: Promozione Della Ricerca Scientifica e Dell'innovazione Tecnologica in Sardegna".

\section{Disclosure statement}

Authors declare they do not have any competing financial, professional, or personal interests from other parties.

\section{References}

AECOM/ITS. 2010. Freight Modal Choice Study. AECOM Transportation / Institute for Transport Studies (ITS), University of Leeds, UK. 212 p.

Allen, J.; Browne, M.; Woodburn, A.; Leonardi, J. 2014. A review of urban consolidation centres in the supply chain based on a case study approach, Supply Chain Forum: an International Journal 15(4): 100-112.

https://doi.org/10.1080/16258312.2014.11517361

Allen, J.; Browne, M.; Woodburn, A.; Leonardi, J. 2012. The role of urban consolidation centres in sustainable freight transport, Transport Reviews 32(4): 473-490.

https://doi.org/10.1080/01441647.2012.688074 
Bahinipati, B. K.; Kanda, A.; Deshmukh, S. G. 2009. Horizontal collaboration in semiconductor manufacturing industry supply chain: an evaluation of collaboration intensity index, Computers \& Industrial Engineering 57(3): 880-895. https://doi.org/10.1016/j.cie.2009.03.003

Bertuccio, L.; Maldacea, R.; Sorge, M.; Gargiulo, O. 2015. Mobilità Sostenibile in Italia: Indagine sulle principali 50 città. Euromobility, Roma, Repubblica Italiana. 38 p. (in Italian).

Bristol City Council. 2013. Key Informant Interview Conducted. 25/04/2013. Available from Internet: https://www.bristol.gov.uk

Browne, M.; Allen, J. 2011. Enhancing the sustainability of urban freight transport and logistics, Transport and Communications Bulletin for Asia and the Pacific 80: 1-19.

Browne, M.; Sweet, M.; Woodburn, A.; Allen, J. 2005. Urban Freight Consolidation Centres: Final Report. Transport Studies Group, University of Westminster, UK. 191 p.

Browne, M.; Woodburn, A.; Allen, J. 2007. The role of urban consolidation centres for different business sectors, in 11th World Conference on Transport Research, 24-28 June 2007, Berkeley, CA, US, 1-20.

Dablanc, L. 2011. City distribution, a key element of the urban economy: guidelines for practitioners, in C. Macharis, S. Melo (Eds.). City Distribution and Urban Freight Transport: Multiple Perspectives, 13-36.

https://doi.org/10.4337/9780857932754.00007

Doig, J. W. 2002. Empire on the Hudson. Columbia University Press. 620 p.

EC. 2011. White Paper: Roadmap to a Single European Transport Area - Towards a Competitive and Resource Efficient Transport System. COM(2011) 144 final. 28.3.2011, Brussels. Available from Internet: http://eur-lex.europa.eu/legal-content/EN/ ALL/?uri=CELEX:52011DC0144

Eisenhardt, K. M. 1989. Building theories from case study research, Academy of Management Review 14(4): 532-550. https://doi.org/10.5465/amr.1989.4308385

Fransoo, J. C.; Blanco, E. E.; Mejía-Argueta, C. 2017. Reaching 50 Million Nanostores: Retail Distribution in Emerging Megacities. CreateSpace Independent Publishing Platform. 440 p.

Gonzalez-Feliu, J.; Malhéné, N.; Morganti, E.; Morana, J. 2014. The deployment of city and area distribution centers in France and Italy: comparison of six representative models, Supply Chain Forum: an International Journal 15(4): 84-99. https://doi.org/10.1080/16258312.2014.11517353

Gonzalez-Feliu, J.; Morana, J. 2011. Collaborative transportation sharing: from theory to practice via a case study from France, in J. Yearwood, A. Stranieri (Eds.). Technologies for Supporting Reasoning Communities and Collaborative Decision Making: Cooperative Approaches, 252-271.

https://doi.org/10.4018/978-1-60960-091-4.ch014

Gonzalez-Feliu, J.; Salanova, J.-M. 2012. Defining and evaluating collaborative urban freight transportation systems, Procedia Social and Behavioral Sciences 39: 172-183.

https://doi.org/10.1016/j.sbspro.2012.03.099

Goodman, R. W. 2005. Whatever you call it, just don't think of last-mile logistics, last, Global Logistics \& Supply Chain Strategies 9(12): 46-51.

Holguín-Veras, J.; Polimeni, J.; Cruz, B.; Xu, N.; List, G.; Nordstrom, J.; Haddock, J. 2005. Off-peak freight deliveries: challenges and stakeholders' perceptions, Transportation Research Record: Journal of the Transportation Research Board 1906: 42-48. https://doi.org/10.3141/1906-05

Holguín-Veras, J.; Sánchez-Díaz, I. 2016. Freight demand management and the potential of receiver-led consolidation programs, Transportation Research Part A: Policy and Practice 84: 109-130. https://doi.org/10.1016/j.tra.2015.06.013
Holguín-Veras, J.; Silas, M.; Polimeni, J.; Cruz, B. 2008. An investigation on the effectiveness of joint receiver-carrier policies to increase truck traffic in the off-peak hours. Part II: the behavior of carriers, Networks and Spatial Economics 8(4): 327-354. https://doi.org/10.1007/s11067-006-9011-6

Kiba-Janiak, M.; Cheba, K. 2011. An assessment of individual transport in the aspect of quality of life on the example of selected medium sized cities, Total Logistic Management (4): 77-88.

Kiba-Janiak, M.; Cheba, K. 2015. Reference model of local authority cooperation with stakeholders for urban freight transport, in Proceedings of the URBE 2015: Urban Freight and Behavior Change, 1-2 October 2015, Rome, Italy.

Kin, B.; Verlinde, S.; Van Lier, T.; Macharis, C. 2016. Is there life after subsidy for an urban consolidation centre? an investigation of the total costs and benefits of a privately-initiated concept, Transportation Research Procedia 12: 357-369. https://doi.org/10.1016/j.trpro.2016.02.072

Köhler, U. 2004. New ideas for the city-logistics project in Kassel, in E. Taniguchi, R. G. Thompson (Eds.). Logistics Systems for Sustainable Cities, 321-332. https://doi.org/10.1108/9780080473222-023

Lindholm, M; Browne, M. 2013. Local authority cooperation with urban freight stakeholders: a comparison of partnership approaches, European Journal of Transport and Infrastructure Research 13(1): 20-38.

Marcucci, E.; Danielis, R. 2008. The potential demand for a urban freight consolidation centre, Transportation 35(2): 269284. https://doi.org/10.1007/s11116-007-9147-3

Martin, C. J. 2016. The sharing economy: a pathway to sustainability or a nightmarish form of neoliberal capitalism?, Ecological Economics 121: 149-159. https://doi.org/10.1016/j.ecolecon.2015.11.027

McKinnon, A. 2010. Green logistics: the carbon agenda, Log Forum 6(3): 1-9.

Montoya-Torres, J. R.; Muñoz-Villamizar, A.; Vega-Mejía, C. A. 2016. On the impact of collaborative strategies for goods delivery in city logistics, Production Planning \& Control: the Management of Operations 27(6): 443-455. https://doi.org/10.1080/09537287.2016.1147092

Muñoz-Villamizar, A.; Montoya-Torres, J. R.; Vega-Mejía, C. A. 2015. Non-collaborative versus collaborative last-mile delivery in urban systems with stochastic demands, Procedia CIRP 30: 263-268. https://doi.org/10.1016/j.procir.2015.02.147

OECD. 2003. Delivering the Goods: 21st Century Challenges To Urban Goods Transport. Organisation for Economic Co-Operation and Development (OECD) Publishing. 153 p. Available from Internet: https://www.itf-oecd.org/sites/default/ files/docs/03deliveringgoods.pdf

Paché, G. 2008. Efficient urban e-logistics: mutualization of resources and source of competitive advantage, in Proceedings of the 7th International Meeting for Research in Logistics (RIRL 2008), 24-26 September 2008, Avignon, France.

Paddeu, D.; Fadda, P.; Fancello, G.; Parkhurst, G.; Ricci, M. 2014. Reduced urban traffic and emissions within urban consolidation centre schemes: the case of Bristol, Transportation Research Procedia 3: 508-517.

https://doi.org/10.1016/j.trpro.2014.10.032

Paddeu, D.; Fancello, G.; Fadda, P. 2017. An experimental customer satisfaction index to evaluate the performance of city logistics services, Transport 32(3): 262-271. https://doi.org/10.3846/16484142.2016.1146998

Patier, D. 2006. New concepts and organisations for the last mile: French experiments and their results, in E. Taniguchi, 
R. G. Thompson (Eds.). Recent Advances in City Logistics, 361-374.

SLDS. 2005. Vraaggestuurd Bundelen. Stichting Leve De Stad (SLDS), Amsterdam. (in Dutch).

Taniguchi, E. 2014. Concepts of city logistics for sustainable and liveable cities, Procedia - Social and Behavioral Sciences 151: 310-317. https://doi.org/10.1016/j.sbspro.2014.10.029

Taniguchi, E.; Tamagawa, D. 2005. Evaluating city logistics measures considering the behavior of several stakeholders, Journal of the Eastern Asia Society for Transportation Studies 6: 3062-3076. https://doi.org/10.11175/easts.6.3062

Triantafyllou, M. K.; Cherrett, T. J.; Browne, M. 2014. Urban freight consolidation centers: case study in the UK retail sector, Transportation Research Record: Journal of the Transportation Research Board 2411: 34-44.

https://doi.org/10.3141/2411-05

Tseng, Y.-Y.; Yue, W. L.; Taylor, M. A. 2005. The role of transportation in logistics chain, Proceedings of the Eastern Asia Society for Transportation Studies 5: 1657-1672.

UN. 2012. World Urbanization Prospects: the 2011 Revision. United Nations (UN), Department of Economic and Social Affairs: Population Division. 318 p. Available from Internet: http://www.un.org/en/development/desa/population/publications/pdf/urbanization/WUP2011_Report.pdf

Van der Poel, W. 2000. Leyden Car(e) Free: an Integral Approach to a Better Environment in an Old City. Gemeente Leiden, Leiden, The Netherlands.

Van Duin, R. 2009. To be or not to be, a typical city distribution centre question. Research on success and failures in ten European CDC-cases, in Bijdragen Vervoerslogistieke Werkdagen, The Netherlands, 123-145.

Van Rooijen, T.; Quak, H. J. 2009. Binnenstadservice.nl - a new type of urban consolidation centre, in European Transport Conference 2009, 5-7 October 2009, Leeuwenhorst Conference Centre, The Netherlands, 1-14.

Van Rooijen, T.; Quak, H. 2010. Local impacts of a new urban consolidation centre - the case of Binnenstadservice.nl, Procedia - Social and Behavioral Sciences 2(3): 5967-5979. https://doi.org/10.1016/j.sbspro.2010.04.011

Verlinde, S.; Macharis, C.; Witlox, F. 2012. How to consolidate urban flows of goods without setting up an urban consolidation centre?, Procedia - Social and Behavioral Sciences 39: 687-701. https://doi.org/10.1016/j.sbspro.2012.03.140

Walker, H.; Di Sisto, L.; McBain, D. 2008. Drivers and barriers to environmental supply chain management practices: Lessons from the public and private sectors, Journal of Purchasing and Supply Management 14(1): 69-85. https://doi.org/10.1016/j.pursup.2008.01.007

Witkowski, J.; Kiba-Janiak, M. 2014. The role of local governments in the development of city logistics, Procedia - Social and Behavioral Sciences 125: 373-385.

https://doi.org/10.1016/j.sbspro.2014.01.1481

Zenezini, G.; Mangano, G.; Cagliano, A. C.; De Marco, A. 2015. A conceptual framework for evaluating City Logistics business models, in Proceedings of the URBE 2015: Urban Freight and Behavior Change, 1-2 October 2015, Rome, Italy.

Zhang, D.; Eglese, R.; Li, S. 2018. Optimal location and size of logistics parks in a regional logistics network with economies of scale and $\mathrm{CO}_{2}$ emission taxes, Transport 33(1): 52-68. https://doi.org/10.3846/16484142.2015.1004644

Zunder, T. H.; Ibanez, J. N. 2004. Urban freight logistics in the European Union, European Transport \Trasporti Europei 28: 77-84.

Zunder, T.; Marinov, M. 2011. Urban freight concepts and practice: would a traditional UCC scheme work?, Transport Problems 6(1): 87-95. 